\title{
Diagnosis and management of chronic fatigue syndrome/myalgic encephalitis in black and minority ethnic people: a qualitative study
}

\author{
Kerin Bayliss ${ }^{1}$, Lisa Riste ${ }^{2}$, Louise Fisher ${ }^{3}$, Alison Wearden ${ }^{4}$, Sarah Peters ${ }^{5}$, Karina Lovell ${ }^{6}$ and \\ Carolyn Chew-Graham ${ }^{7}$ \\ ${ }^{1}$ Research Associate, Institute of Population Health, University of Manchester, Manchester, UK \\ ${ }^{2}$ Research Fellow, Institute of Population Health, University of Manchester, Manchester, UK \\ ${ }^{3}$ Academic Clinical Fellow, National School for Primary Care Research, University of Manchester, UK \\ ${ }^{4}$ Professor of Health Psychology, School of Psychological Sciences, University of Manchester, Manchester, UK \\ ${ }_{5}^{5}$ Senior Lecturer in Psychology, School of Psychological Sciences, University of Manchester, Manchester, UK \\ ${ }^{6}$ Professor of Mental Health, School of Nursing, Midwifery and Social Work, University of Manchester, Manchester, UK \\ ${ }^{7}$ Professor of Primary Care, Primary Care and Health Sciences and National School for Primary Care Research, \\ Keele University, UK
}

\begin{abstract}
Aim: This study aims to explore the possible reasons for the lower levels of diagnosis of chronic fatigue syndrome/myalgic encephalitis (CFS/ME) in the black and minority ethnic (BME) population, and the implications for management. Background: Population studies suggest $\mathrm{CFS} / \mathrm{ME}$ is more common in people from BME communities compared with the White British population. However, the diagnosis is made less frequently in BME groups. Methods: Semi-structured qualitative interviews were conducted with 35 key stakeholders in NW England. Interviews were analysed using open explorative thematic coding. Findings: There are barriers at every stage to the diagnosis and management of $\mathrm{CFS} / \mathrm{ME}$ in people from BME groups. This begins with a lack of awareness of CFS/ME among BME respondents. Religious beliefs and the expectation of roles in the family and community mean that some people in BME groups may choose to manage their symptoms outside primary care using alternative therapies, prayer or spiritual healing. When accessing primary care, all participants recognised the possible influence of language barriers in reducing the likelihood of a diagnosis of CFS/ME. Stereotypical beliefs, including labels such as 'lazy' or 'work shy' were also believed to act as a barrier to diagnosis. Patients highlighted the importance of an on-going relationship with the general practitioner (GP), but perceived a high turnover of GPs in inner city practices, which undermined the holistic approach necessary to achieve a diagnosis. Conclusion: Training is required for health professionals to challenge inaccurate assumptions about $\mathrm{CFS} / \mathrm{ME}$ in BME groups. The focus on the individual in UK primary care may not be appropriate for this group due to the role played by the family and community in how symptoms can be presented and managed. Culturally sensitive, educational resources for patients are also needed to explain symptoms and legitimise consultation.
\end{abstract}

Keywords: access to care; black and minority ethnic; CFS/ME; chronic fatigue syndrome/myalgic encephalitis; diagnosis and management; primary care

Received 23 July 2012; revised 7 March 2013; accepted 10 March 2014;

first published online 23 May 2013

Correspondence to: Kerin Bayliss, Institute of Population Health, University of Manchester, 7th Floor Williamson Building, Oxford Road, Manchester M13 9PL, UK. Email: kerin.bayliss@manchester.ac.uk

C) Cambridge University Press 2013 


\section{Introduction}

Chronic fatigue syndrome (CFS) or myalgic encephalitis (ME) is characterised by severe, disabling, medically unexplained fatigue that is not alleviated by rest and lasts at least six months (National Institute for Health and Clinical Excellence (NICE), 2007). Symptoms can differ between patients but can include headaches, unrefreshing sleep, weakness, pain and concentration or memory problems (Fukuda, 1994). The condition is distressing and is costly in terms of both health service utilisation and economic burden to patients and their families (Assefi et al., 2003; Collin et al., 2011).

National guidelines such as NICE emphasise the importance of an early diagnosis (NICE, 2007). However, previous research has revealed that there are barriers to diagnosis, and some general practitioners (GPs) remain sceptical about the condition (Chew-Graham et al., 2008; Drachler et al., 2009; Hannon et al., 2012). In a recent primary care treatment trial (Wearden et al., 2010), the mean time from onset of symptoms to diagnosis was 3.6 years. It is likely therefore that at any one time a number of individuals are awaiting diagnosis, suggesting the UK prevalence of CFS/ME of $0.2-0.4 \%$ (Department of Health, 2002) is likely to be a low estimate. NICE guidance also recommends that patients with CFS/ME receive early treatment with the use of tailored care-packages (NICE, 2007). However, this rarely happens in practice, and $65 \%$ of the Action for ME members surveyed report never receiving any treatment for their CFS/ME (Action for ME (AFME), 2001).

Studies in the United Kingdom and United States have shown that ethnic minority groups have a higher prevalence of CFS/ME than White groups, but are less likely to be diagnosed (Dinos et al., 2009; Horton et al., 2010; Bhui et al., 2011). This suggests that these groups may face additional barriers to the diagnosis and treatment of CFS/ME. Without a diagnosis, patients can experience more severe symptoms and develop unhelpful illness beliefs or management styles, which then become entrenched making any subsequent treatment more difficult (Phelby and Saffron, 2004). Despite these findings, relatively few studies have investigated the problem of CFS/ME in BME people (Torres-Harding, 2002).

This paper presents the findings of a qualitative study exploring the possible reasons why people from BME groups may be less frequently diagnosed with CFS/ME.

\section{Methods}

\section{Ethics}

Ethical approval was obtained from the Greater Manchester East Ethics Committee (10/H1001/5).

\section{Design}

Semi-structured interviews were conducted with $11 \mathrm{BME}$ people with $\mathrm{CFS} / \mathrm{ME}$, two carers, nine GPs, five practice nurses (PNs), four CFS/ME specialists and five BME community leaders (Appendix) in North West England.

\section{Sampling}

A purposive sample of BME patients and carers were recruited through existing CFS/ME support groups, and South Asian community groups. KB visited these groups to promote the study, distributing project flyers in English, Hindi and Urdu. South Asian groups were chosen as these are highlighted as having a higher prevalence of $\mathrm{CFS} / \mathrm{ME}$ in the literature, and are also the most common BME group in the North West (Bhui et al., 2011). The research team had previously established links with these groups, making access to this hard to reach population slightly easier. Other participants were recruited through specialist CFS/ME services in the National Health Service (NHS) in response to a project flyer.

A purposive sample of general practices was contacted giving information about the study and inviting GPs to participate. We attempted to sample on size of practice and demographics (inner city/urban/sub-urban; ethnic mix). GPs who expressed an interest were invited to participate in an interview. PNs were recruited by a variety of methods. First, all GPs interviewed were asked to forward details of the study on to PNs in their practice. Second, a project flyer was sent out to all lead PNs in two primary care trusts, inviting them to participate and asking them to forward the details on to the rest of their PN forum. Finally, one PN was recruited through a contact with a patient involvement group (in the METRIC* study: Hannon et al., 2012). A letter of invitation and an information sheet were sent to CFS/ME specialists working in local CFS/ME 
services inviting them to participate in a semistructured interview.

It became apparent after interviewing $\mathrm{BME}$ patients that community and religious leaders had contributed to the likelihood of presenting to healthcare services and receiving a diagnosis of $\mathrm{CFS} / \mathrm{ME}$. We thus sought to include the views of this group of stakeholders. A letter of invitation and an information sheet were sent to managers of South Asian third sector groups in Greater Manchester.

\section{Data Collection}

Face-to-face semi-structured interviews were conducted, with consent, with all participants during 2011-2012. Topic guides (available from the authors) were developed by the research team based on a review of the literature and the research team's experience. BME patient/carer interviews focussed on experiences of accessing primary care, illness models, the attitudes of family and the community and sources of support. Community leaders' interviews explored understanding of $\mathrm{CFS} / \mathrm{ME}$ and the role of the family, community, primary care and religion in the diagnosis and management of the condition. Health practitioner interviews focussed on current practice, attitudes towards $\mathrm{CFS} / \mathrm{ME}$ and perceived barriers faced making the diagnosis and managing CFS/ME in people in BME groups.

\section{Analysis}

Interviews were digitally recorded and transcribed verbatim. Analysis was conducted in parallel with the interviews and was inductive, using components of thematic analysis (Huberman and Miles, 1994) that were in line with modified grounded theory (Neuman, 2000). Thematic categories were identified in initial interviews and then explored in subsequent interviews. Disconfirming evidence was used to modify emerging themes. Main categories were then compared across interviews and reintegrated into common themes (Silverman, 1997; Neuman, 2000). Interview transcripts were read, annotated and categorised independently by all authors to increase reliability and subsequently discussed as a group. As this study was explorative, not theoretical, open coding was used rather than axial or selective coding (Strauss and Corbin, 1990). The authors agreed theoretical saturation was achieved when no new ideas emerged during the final interviews and across data sets.

\section{Results}

Analysis of the data focussed on key issues that impact on the diagnosis and management of CFS/ $\mathrm{ME}$ in people from BME groups. Six key themes were identified: models of illness; access to care; language and understanding; family and community; religion and culture; and stereotypes and racism.

\section{Models of illness}

Both community leaders and health professionals described how they perceived that many BME patients held a biomedical model of illness and therefore would focus on presenting physical symptoms such as headaches and muscle pain when consulting with their GP. They suggested BME people would be more likely to refrain from seeking medical advice about non-specific symptoms such as fatigue, loss of concentration and problems with sleep. This was believed to act as a barrier to the diagnosis of $\mathrm{CFS} / \mathrm{ME}$ :

'South Asians do somatise, they think the GP can only help with physical problems like pain'.

(Community leader 2, male, Pakistani)

Some GPs and community leaders described $\mathrm{CFS} / \mathrm{ME}$ as a 'psychosocial condition', which might be more difficult to explain to people from some BME groups:

'There's always a bit of a problem with Afro-Caribbean patients... getting them to see that the difficulties that they have had in their personal lives can have an impact on them physically is actually quite difficult. So if you extrapolate that to something like chronic fatigue, I think that could be quite a difficult area to get into'.

(GP2, male, White British)

One community leader also suggested that the close community support can act as a protective factor against $\mathrm{CFS} / \mathrm{ME}$ :

'This problem of [chronic] fatigue syndrome may be more related to the social problems than actually physically not feeling too well. This is my opinion... I'd just like to say that our people 
don't suffer from chronic fatigue, because we are always in the company of friends, relations, children, grandchildren and all that'.

(Community leader 1, male, Indian)

Fatigue was reported to be part of the expected aging process in some BME communities, which was thought to explain why some patients fail to seek medical help:

'The way they look at medicine is different. Some of the ladies that used to come to the surgery where I worked, they'd say oh well, I am a certain age and I expect to be like this. So I don't know whether there was an expectation that that's how they should be, and they should just adapt themselves to that'.

(PN 4, female, White British)

However, patients and community leaders also suggested that health professionals might focus on physical symptoms and patients may not be encouraged to discuss non-specific symptoms such as fatigue:

'They don't help us for fatigue... And I don't know why... Then I think well, what's the point of saying?... Sometimes it's kind of frustration because they don't really do anything. They don't help you in this way'.

(Patient 3, female, Pakistani)

Models of illness were therefore seen to vary across the different respondents illustrating the problems that may be encountered in a primary care consultation.

\section{Access to care}

Most patients reported that their usual family doctor was from a BME community. However, only one patient reported receiving the diagnosis of CFS/ME from a non-Caucasian GP. The others reported being diagnosed by a White British GP. Patients and community leaders described how GPs who were family friends or part of the community might be less likely to suggest a diagnosis of CFS/ME. In addition, patients described how they had changed GPs in order to receive a diagnosis, often relying on recommendations from other people with $\mathrm{CFS} / \mathrm{ME}$ :

'The problem with the Asian GPs is they become like friends of the family. Now when you're going to the GP, it's better for him to be like a professional person, because they've known some of these older people, you know, maybe 30-odd years and he's seen them grow. And sometimes they have the attitude "oh well, it's age, old age has caught up to you". The doctor just says "oh look after him", and all that, you know, and not really referring them on to the hospital to be diagnosed properly'.

(Community leader 3, male, Pakistani)

'I could imagine like my family doctor when I was back at home if I went in and said something like that to him he'd probably laugh me out of the door, you know, so I think some of it's like the fear of what people will think... A friend knew someone who had been diagnosed by another GP so I signed up with that practice'.

(Patient 5, male, Indian)

Patients and health professionals also described how BME patients were often unaware of CFS/ME and would not seek further support from primary care if they are told that there was nothing physically wrong with them:

'If somebody has got a lot of respect for the medical profession and they say there's nothing wrong with you... you just take that as, there's nothing wrong with you. It's so intangible... It takes a lot of doctor-bothering [as well], and that's not something which I enjoy doing... Maybe there's a sense of pride in certain communities because... it does feel like you're whingeing'.

(Patient 4, female, Other White)

'I think it's a diagnosis that you fish for and people push for... [BME people] don't come back and see us... It is a problem but they just carry on. We don't really have [BME] people pushing us to make diagnoses of chronic fatigue, so it doesn't really happen that often... It's not to do with, "I have chronic fatigue syndrome"... That's not where they're at... [The white population], they know about the diagnosis, they may well ask for it'.

(GP4, female, White British)

The high turnover of GPs in the inner city practices that may provide care for people in 
BME communities was cited as a reason why some people may not receive a diagnosis of CFS/ME. Patients believed that a lack of continuity meant that they were unable to build a long-term relationship with their health professional and GPs were unable to take the holistic approach considered necessary for the diagnosis of $\mathrm{CFS} / \mathrm{ME}$ to be made:

'...in a city, GPs, they change so much. I mean I think we've had about four years of locum GPs and there becomes a point at which even the patient becomes despondent, whereby you're thinking how much of my soul do I have to give before I get a service? Any good relationship... is also about consistency. And if that continues to change there becomes a point at which the information only becomes partial; there's not always a full picture... It's almost like a conveyor belt of symptom spotting... you can go to your doctor and say I'm tired all the time. He's going to tell me maybe you need to lose some weight or you need to eat better or exercise, and then he's gone. And there's nothing else about me that he's looking at'.

(Patient 10, female, Black British)

As a result of negative experiences with the GP around the presentation of non-specific symptoms such as fatigue, some patients reported that they had chosen not to consult in the future and would prefer to manage symptoms themselves:

'If I'm honest I've tried very much to refrain from going to the GP, and whatever symptoms I have now I try to, unless it's something I think is really, really severe, is to manage it myself whatever it is...'.

(Patient 10, female, Black British)

Other patients reported a preference to see the Hakim or herbalist if they experienced symptoms of $\mathrm{CFS} / \mathrm{ME}$ as they speak their language and are able to spend more time with the patient:

'You know, they say go to the Hakim or, you know, go to the alternatives, it's there in India and Pakistan and Bangladesh... it's not something that's alien to them ...they'll feel more comfortable... Especially if you do speak their language and everything, [they are] more sympathetic and empathetic [than the GP]... understanding the values, the traditions, the background, the whole thing'.

(Community leader 4, female, Pakistani)

'Hakim is, you could say, a kind of doctor, who specialises in this kind of herbal stuff... Sometimes they would access Hakim in Pakistan, who they feel are more qualified and more experienced...they spend time with you... you have to pay but they also prescribe modern drugs in Pakistan'.

(Community leader 3, male, Pakistani)

\section{Language and understanding}

Health professionals, patients, carers and community leaders agreed that not speaking English acts as a barrier to the diagnosis and management of $\mathrm{CFS} / \mathrm{ME}$. Some BME patients are not able to adequately describe their symptoms or understand the GP during a consultation. As CFS/ME is a diagnosis of exclusion, a number of appointments and investigations are required to reach diagnosis, which is made more difficult when communication is difficult:

'There is effort involved of drawing out somebody's symptoms, if English isn't their first language, it will be a longer consultation. It's easier to say oh you're probably anaemic... come back to me... and just sort of, I don't know, just not fob them off but I guess there's an element of having to rush through consultations'.

(PN 1, female, White British)

Some patients described visiting the GP with English speaking family members, or using brief notes written by community leaders to outline symptoms. Others relied on professional interpreters who may not understand their regional dialect, or misinterpret their symptoms. As $\mathrm{CFS} / \mathrm{ME}$ is a complex, medically unexplained condition, health professionals stated that the use of interpreters can present a barrier when trying to achieve a diagnosis or advice about management:

'We do work through interpreters, but because you are not just giving instruction, you are trying to get over a concept, sometimes you can see that the interpreter is 
engaged with it and you can set goals, other times, the interpreter is just telling them to just do the exercises. The tone isn't right you know'.

(CFS/ME specialist 2, female, White British)

'It's not the same having a three-way conversation as opposed to having a dialogue one to one and how they can express the tone and all that, it's just different, a three-way conversation'.

(PN3, female, Pakistani)

If a person cannot read English, community leaders described that this limits their ability to research their symptoms using the internet or books possibly resulting in a lack of awareness of CFS/ME when compared with the White population:

'A lot of the South Asian communities, especially the women that I work with, are illiterate, some of them can't even access an internet, or they might not even have an internet at home.... I don't think they would even know how to research it...'.

(Community leader 5, female, Pakistani)

When a patient who does not have English as their first language is diagnosed, it was reported that they may find the words 'Chronic Fatigue Syndrome' difficult to understand:

'We have words for tiredness... but they just wouldn't understand that [terminology]. The ordinary person or person that doesn't speak English, you know... would not understand the word fatigue ... or syndrome'.

(Community leader 3, male, Pakistani)

\section{Family and community}

The expectation to fulfil certain roles within the family or community was described as a barrier to the diagnosis and management of CFS/ME. Patients and CFS/ME specialists explained how a woman's role to prioritise and care for her family often meant that there may be no time or support to seek medical advice for non-specific symptoms such as fatigue. Community leaders and CFS/ME specialist practitioners also stated that some BME families would only allow a woman to rest or engage in physical activity if it was recommended by the GP. Some patients reported distancing themselves from the family unit in order to manage their symptoms:

'Most people, they don't take the help, they might be bad, but, they won't take it... Some [in-laws] expect women to do everything. So, what, she's tired, so, she still has to do things... I was lucky, I was away from everyone, you see, it would be harder with the family around me, they just come in and expect you to cook for them, or, you know, have visitors in and out, I didn't have that'.

(Patient 7, female, Pakistani)

'When things come from the GP, it's more respected, so if the GP said to a woman, you have to go and do exercise and the husband was told, then, he would allow her to, but if the woman said to her husband, generally, that I want to go and do exercise, then, there'd be all this complication, where are you going to fit it in? You know, you're going to neglect the kids, you're not going to put enough time in the house... if you're living in an extended family, it all has to be explained to them, what's going on and why'.

(Community leader 5, female, Pakistani)

Some South Asian patients commented on the pressure from their family to push themselves academically to be a 'high achiever' and maintain a successful career. The perceived stigma attached to low academic achievement pushed some patients to ignore symptoms of CFS/ME until they reached a crisis point:

'Most Asian families are quite sort of pushy and they still want their children to succeed and be working in good jobs, and things like this. So they were quite worried, at what's going on here. And I told them, I'm ill. And they said, "Well, what's wrong with you?" "I don't know. I just feel really tired. I don't have energy", and stuff like that... they were just saying, "Well, just get on with it'.

(Patient 8, male, Pakistani)

Community leaders and health professionals described how some people turn to their family rather than a GP when they feel unwell and it 
was suggested that large families adapt to accommodate or manage fatigue in one member:

'These people when they are not well or they have any sort of pain they will first talk to their children... So the first port of call is their children... It would be rather dealt with within the family circle, like their close friends, relations and all that'.

(Community leader 2, male, Pakistani)

'Perhaps some ethnic minority groups are more accepting if they have a big family structure. If someone's feeling tired then perhaps they're more likely to nurture them and allow them to spend the afternoon in bed on a regular basis and not question it as well... there's a strong support network'.

(GP8, female, White British)

\section{Religion and culture}

Patients and community leaders described how some BME people would turn to religion or spiritual healers rather than primary care when experiencing fatigue believing that spirits or black magic may be causing the condition:

'Black people don't tend to...they think if you go to church...that they'll pray for you. You don't need medical intervention... They said it's a demon controlling all your illnesses... they believe a lot in witchcraft. It's somebody in your family doing something to make you ill... My mum says all the time that I'm weak or something. It's somebody that's doing something to make me weak'.

(Patient 9, female, Black British)

'If you do get symptoms like that, sometimes within the Asian culture, people think it's due to sort of black magic or something like that. And that's the first thing they think of. They think, "Oh somebody's cast a spell on him", or something like that... People don't think, "Oh this may be a medical thing. I need to go to my GP or get medical attention'. Instead they think, "Oh I need a sort of spiritual healer for this type of thing'.

(Patient 8, male, Pakistani)

'I know a lot of people, you know, who certainly believe that their health problems are more related to the supernatural ... you know like what is known as Jin'.

(Community leader 4, female, Pakistani)

Religion and prayer were also cited as motivators for patients to attempt to manage their symptoms and not seek medical advice:

'Spiritually I like to do stuff, I think, that's one of the things that keeps me going, as well, that's my condition, you know, when I'm praying or, because, I have to, like, get up and I have to go wash myself so I can pray, so just stuff like that helps me as well'.

(Patient 7, female, Pakistani)

'In most cases, if they are mobile they will come to the temple and that would take a lot of load off their mind so that they come and then go into the temple, sing their religious songs and all that. And that would more or less relieve quite a bit of pain and things like that'.

(Community leader 1, male, Indian)

White British health professionals in this study were not aware of the barriers posed by religious or spiritual beliefs in the diagnosis and management of $\mathrm{CFS} / \mathrm{ME}$ in primary care. This suggests that the patient may not discuss these beliefs with their GP:

'Nobody's really discussed religion with me... I don't know much about that'.

(PN5, female, White British)

\section{Stereotypes and racism}

Patients, carers and community leaders described how they believed that some GPs may hold stereotypical views of people from certain cultures such as being 'lazy', 'complainers' or 'work shy', that might prevent the diagnosis of CFS/ME:

'I think there's a perception that exists of Afro-Caribbean people, that although may not be spoken exists and has permeated through society for a long time, in that you've got certain groups that are lazy, work-shy, uneducated.... When you go to the GP there's a perception that maybe you don't have those things, you're just tired because either you've got a full life or you're not fully understanding of what your situation is'.

(Patient 10, female, Black British) 
'I went [to the GP]... he's telling me that there's nothing wrong with your husband, he's being lazy. And that really got me so angry... he hates anybody questioning his honesty and his willingness to work, so if anybody even slightly suggests that he's being lazy, pull your socks...oh, he feels so hurt that it really puts him down, really down'.

(Carer 1, female, Indian)

Health professionals recognised the possible influence of racism and stereotypes, in preventing the diagnosis of $\mathrm{CFS} / \mathrm{ME}$ :

'A lot of Asian women say they are depressed and miserable because they can't do anything, they're in pain all the time... and lots of [GPs] just say oh they're just grumpy, moaning, Asian women...'.

(GP 1, female, White British)

Community leaders also described how people with CFS/ME could be given stigmatising labels such as 'lazy', 'liars' or 'crazy' by their community and BME patients may therefore want to avoid this potentially stigmatising diagnosis:

'I think people in the Asian community would think well what, we've never heard of that one, what's this, are they just being a lazy bugger kind of thing. Yeah, I think because of the lack of understanding of the illness, it's not like it's heart disease, diabetes, that kind of thing. So I think yes, people would be sceptical, you know, what's this, she's got a new illness but is she making it up, has she just become lazy'.

(Community leader 4, female, Pakistani)

\section{Discussion}

\section{Summary of the main findings}

This is the first study to explore the perspectives of a range of stakeholders in order to identify barriers to the diagnosis and management of $\mathrm{CFS} / \mathrm{ME}$ in people from BME groups. The findings suggest that barriers can occur for patients evaluating their own symptoms, accessing primary care and within the GP consultation. People from BME groups report only consulting with their GP for physical symptoms such as pain; turning to alternative therapies, religious prayer and spiritual healing for the non-specific symptom of fatigue. The need to fulfil certain roles within the family and community can also mean that some BME people feel unable to access primary care. A large family unit may, however, adapt to accommodate fatigue in one member, or people may ignore symptoms for fear of being labelled as 'lazy' within their community.

Language was highlighted by all participants as a barrier to the discussion of fatigue, and the GP may be reluctant to provide a diagnosis of $\mathrm{CFS} / \mathrm{ME}$ due to a number of assumptions about the aetiology of CFS/ME or the patient group. It was reported that GPs from BME groups were less likely to provide a diagnosis of $\mathrm{CFS} / \mathrm{ME}$. Without a diagnosis, it was reported that some people may not be able to manage their symptoms as they can be forced to continue inappropriate levels of activity by their family.

\section{Strengths and limitations of the study}

A strength of this study is that a range of stakeholders; including patients, carers, community leaders and health professionals, were interviewed to provide insight into the barriers faced in both obtaining and providing a diagnosis of CFS/ME in $\mathrm{BME}$ groups. By reporting the barriers that can arise from the assumptions and beliefs held by the patient, health professional and community, this study highlights the complexity of gaining a diagnosis of $\mathrm{CFS} / \mathrm{ME}$ in the BME population.

It was difficult to recruit BME patients and carers due to a lack of awareness of CFS/ME as a medical condition. Most of the patients and carers recruited were educated, middle class, second- or third-generation immigrants. Community leaders were interviewed in order to gain insight into the behaviour and needs of first generation and working class immigrants, and those who cannot speak English. This is valuable data as this group is often hard to reach due to language and cultural barriers (Torres-Harding, 2002; Hoppitt et al., 2012). However, we are aware of the complexities of gathering information from such stakeholders, who may censor information they deem inappropriate to share with outsiders (Kokonovic et al., 2009). In order to uncover information on the barriers to diagnosis we also included some patients who were self diagnosed. This provided valuable data on methods of managing fatigue outside primary care 
but it possible that these patients may not have CFS/ME.

The BME participants in this study were Pakistani, Black British, Indian and Other White; therefore, the views of other ethnic minorities are not represented. It is important to refrain from making generalisations from these data as there will be differences within and between BME groups. It is also important to recognise that not all the findings are unique to BME groups. For example, the need to fulfil family roles and fear of stereotyping can also act as barriers for to the diagnosis and management of CFS/ME for White British people (Chew-Graham et al., 2008). However, the participants in this study describe how such barriers can be exaggerated in BME groups.

\section{Comparison with previous literature}

In accordance with the NICE (2007) guideline, the patients interviewed wanted a positive, early diagnosis and information on how to manage their symptoms. However, self-evaluation of the symptoms of fatigue left patients and their families unsure of whether it was appropriate to consult, thus possessing candidacy (Dixon Woods et al., 2006). The reality reflected previous research, which suggests that people from BME groups can experience barriers to accessing primary care (Husain et al., 2006), and inadequate support if they do access primary care (Dowrick et al., 2009; Peters et al., 2009). Research also describes a lack of empathy, negative attitudes generally towards people with CFS/ME (Bowen et al., 2005; Dickenson et al., 2007; Chew-Graham et al., 2010). When combined with the potential stereotyping and racism reported in this study, people from BME groups experiencing fatigue encounter barriers at all levels to accessing care.

\section{Implications for future research and clinical practice}

The findings of this study support the work of Hannon et al. (2012), who highlight the need for culturally sensitive training for health professionals on how to diagnose and manage CFS/ME. This would include advice on how to develop skills in patient engagement, problem solving and developing a model of the illness in collaboration with the patient. An awareness that some BME patients can focus on physical symptoms such as pain should alert the GP to explore symptoms such as fatigue and think of CFS/ME as a potential diagnosis. There is also a need to highlight the social, cultural and religious norms and practices that can act as a barrier to both diagnosis and management (Drachler et al., 2009). This will equip GPs with the knowledge of how CFS/ME is perceived by this group, and to discuss appropriate and achievable management techniques. For example, the concept of 'taking time for yourself' and graded activity (White et al., 2011), may not be feasible without the GP discussing the benefits of this approach with family members who may play an important role in the decision to engage with an activity. By incorporating these transferrable skills and concepts into clinical practice, health professionals can also work to reduce barriers faced by BME groups in other medically unexplained and mental health conditions (Dowrick et al., 2009).

Research has shown that cognitive behavioural therapy and graded exercise therapy are effective treatments for CFS/ME (White et al., 2011). However, further research is required into the effectiveness of these interventions in BME groups. This paper highlights that BME people often use their social network, religion and alternative therapy to manage symptoms of $\mathrm{CFS} / \mathrm{ME}$, therefore the impact of these factors on the outcomes of CFS/ME should also be explored.

In order to raise awareness of CFS/ME in BME groups, there is a need to develop and evaluate culturally sensitive information for patients and their families (Hannon et al., 2012). Professional interpreters also require some knowledge of $\mathrm{CFS} / \mathrm{ME}$ in order to accurately relay symptoms and describe ways to manage the condition and further research should evaluate the impact of training professional interpreters about CFS/ME in both a primary care and specialist service setting.

\section{Conclusions and next steps}

People from BME groups may be less frequently diagnosed with CFS/ME than White British groups as a result of barriers to accessing primary care, based on the assumptions and beliefs of the patient, community and health professional, and language and cultural barriers within the GP consultation. GPs must consider 
the impact of the family and community when offering advice about management, challenging the current model of care that places responsibility on the individual to manage their condition (Drachler et al., 2009; Hannon et al., 2012). Materials for BME patients and their families are also required with the aim of raising awareness of the condition, legitimising consultation for fatigue and supporting the diagnosis and management of symptoms.

\section{Acknowledgements}

The authors thank all the patients, carers, GPs, practice nurses and community leaders who gave their time to be interviewed in this study.

\section{Authors' contributions}

KB contributed to the recruitment of participants, patient, carer and community leader data collection, data analysis and drafted the paper. LR contributed to the recruitment of participants, data analysis and writing the paper. LF contributed to the recruitment of participants, GP and practice nurse data collection, data analysis and writing the paper. AW, SP and KL contributed to the data analysis and writing the paper. CCG designed and managed this study. She contributed to the recruitment of participants, CFS/ME specialist data collection, data analysis and writing the paper. CCG is guarantor for the study and paper. All authors read and approved the final manuscript.

\section{Disclaimer}

This paper outlines independent research funded by the National Institute for Health Research (NIHR) under its Research for Patient Benefit Programme (Grant Reference PB-PG-0609-19108). The views expressed are those of the author(s) and not necessarily those of the NHS, the NIHR or the Department of Health.

\section{Funding}

This work was funded by an NIHR Research for Patient Benefit (RfPB) grant. The study is called the METRIC* study.

\section{Competing interests}

The author(s) declare that they have no competing interests.

Primary Health Care Research \& Development 2014; 15: 143-155

\section{Ethical Standards}

Ethical approval was obtained from the Greater Manchester East Ethics Committee (10/H1001/5).

\section{References}

Action for ME (AFME). 2001: Severely neglected - M.E. in the UK. Retrieved 8 June 2012 from www.afme.org.uk.

Assefi, N.P., Coy, T.V., Uslan, D., Smith, W.R. and Buchwald, D. 2003: Financial, Occupational, and personal consequences of disability in patients with Chronic fatigue syndrome and fibromylagia compared to other fatiguing conditions. Journal of Rheumatology 30, 804-08.

Bhui, K.S., Dinos, S., Ashby, D., Nazroo, J., Wessely, S. and White, P.D. 2011: Chronic fatigue syndrome in an ethnically diverse population: the influence of psychosocial adversity and physical inactivity. $B M C$ Medicine 9, 26.

Bowen, J., Pheby, D., Charlett, A. and McNultya, C. 2005: Chronic fatigue syndrome: a survey of GPs' attitudes and knowledge. Family Practice 22, 389-93.

Chew-Graham, C.A., Cahill, G., Dowrick, C., Wearden, A. and Peters, S. 2008: Using multiple sources of evidence about $\mathrm{CFS} / \mathrm{ME}$ in primary care consultations. Annals of Family Medicine 6, 340-48.

Chew-Graham, C., Dowrick, C., Wearden, A., Richardson, V. and Peters, S. 2010: Making the diagnosis of CFS/ME in primary care: a qualitative study. BMC Family Practice 11,16 .

Collin, S.M., Crawley, E., May, M.T., Sterne, J.A.C., Hollingworth, W. and UK CFS/ME National Outcomes Database. 2011: The impact of CFS/ME on employment and productivity in the UK: a cross-sectional study based on the CFS/ME national outcomes database. BMC Health Services Research 11, 217.

Department of Health. 2002: Independent working group: a report of the CFS/ME working group. London: $\mathrm{DH}$, Report to the Chief Medical Officer of an Independent Working Group.

Dickenson, A., Knussen, C. and Flowers, P. 2007: Stigma and the delegitimation experience: an interpretative phenomenological analysis of people living with chronic fatigue syndrome. Health \& Psychology 22, 851-67.

Dinos, S., Khoshaba, B., Ashby, D., White, P.D., Nazroo, J., Wessely, S. and Bhui, K.S. 2009: A systematic review of chronic fatigue, its syndromes and ethnicity: prevalence, severity, co-morbidity and coping. International Journal of Epidemiology 38, 1554-70.

Dixon-Woods, M., Cavers, D., Agarwal, S., Annandale, E., Arthur, A., Harvey, J., Hsu, R., Katbamna, S., Olsen, R., Smith, L., Riley, R. and Sutton, A.J. 2006: Conducting a critical interpretive synthesis of the literature on access to healthcare by vulnerable groups. BMC Medical Research Methodology 6, 35. 
Dowrick, C., Gask, L., Edwards, S., Aseem, S., Bower, P., Burroughs, H., Catlin, A., Chew-Graham, C., Clarke, P., Gabbay, M., Gowers, S., Hibbert, D., Kovandzic, M., Lamb, J., Lovell, K., Rogers, A., Lloyd-Williams, M., Waheed, W. and the AMP Group. 2009: Researching the mental health needs of hard-to-reach groups: managing multiple sources of evidence. BMC Health Services Research 9, 226.

Drachler, M.L., Leite, J.C.C., Hooper, L., Hong, C.S., Pheby, D., Nacul, L., Lacerda, E., Campion, P., Killett, A., McArthur, M. and Poland, F. 2009: The expressed needs of people with chronic fatigue syndrome/ myalgic encephalomyelitis: a systematic review. $B M C$ Public Health 9, 458.

Fukuda, K., Straus, S.E., Hickie, I., Sharpe, M.C., Dobbins, J.G. and Komaroff, A. 1994: The chronic fatigue syndrome: a comprehensive approach to its definition and study. Annals of Internal Medicine 121, 953-59.

Hannon, K.L., Peters, S., Fisher, L., Riste, L., Wearden, A., Lovell, K. and Chew-Graham, C. 2012: Developing resources to support the diagnosis and management of chronic fatigue syndrome/malgic encephalitis (CFS/ME) in primary care. A qualitative study. BMC Family Practice 13, 93.

Hoppitt, T., Shah, S., Bradburn, P., Gill, P., Calvert, M., Pall, H., Fazil, Q. and Sackley, C. 2012: Reaching the 'hard to reach': strategies to recruit black and minority ethnic service users with rare long-term neurological conditions. International Journal of Social Research Methodology 15, 485-95.

Horton, S.M.C., Poland, F., Kale, S., Drachler, M., Leite, J.C.C., McArthur, M.A., Campion, P.D., Pheby, D. and Nacul, L. 2010: Chronic fatigue syndrome/myalgic encephalomyelitis (CFS/ME) in adults: a qualitative study of perspectives from professional practice. BMC Family Practice 11, 89.

Huberman, A.M. and Miles, M.B. 1994: Data management and analysis methods. In Denzin N.K. and Lincoln Y.S., editors, Handbook of Qualitative Research. Thousand Oaks, California: Sage, 428-44.

Husain, M.I., Waheed, W. and Husain, N. 2006: Self-harm in British South Asian women: psychosocial correlates and strategies for prevention. Annals of General Psychiatry. http://www.annals-general-psychiatry.com/content/5/1/7
Kokanovic, R., Furler, J., May, C., Dowrick, C., Herrman, H., Evert, H. and Gunn, J. 2009: The politics of conducting research on depression in a cross-cultural context. Qualitative Health Research 19, 708-17.

Peters, S., Rogers, A., Salmon, P., Gask, L., Dowrick, C., Towey, M., Clifford, R. and Morriss, R. 2009: What do patients choose to tell their doctors? Qualitative analysis of potential barriers to reattributing medically unexplained symptoms. Journal of General Internal Medicine 24, 443-49.

Phelby, D. and Saffron, L. 2004: Risk factors for severe ME/ CFS. Biology and Medicine 1, 50-74.

National Institute for Clinical Excellence (NICE). 2007: Chronic fatigue syndrome/myalgic encephalomyelitis (or encephalopathy): diagnosis and management of $\mathrm{CFS} / \mathrm{ME}$ in adults and children. NICE clinical guideline 53. NHS National Institute for Health and Clinical Excellence. http://www.nice.org.uk/CG53

Neuman, W.L. 2000: Social research methods: qualitative and quantitative approaches. Needham Heights: Allyn and Bacon.

Silverman, D. 1997: Qualitative research: theory, method and practice. London: Sage.

Strauss, A. and Corbin, J. 1990: Basics of qualitative research. London: Sage.

Torres-Harding, S.R., Jason, L.A. and Taylor, R.R. 2002: Fatigue severity, attributions, medical utilization, and symptoms in persons with chronic fatigue. Journal of Behavior Medicine 25, 99-113.

Wearden, A.J., Dowrick, C., Chew-Graham, C., Bentall, R.P., Morriss, R.K., Peters, S., Riste, L., Richardson, G., Lovell, K. and Dunn, G. 2010: Nurse led, home based self help treatment for patients in primary care with chronic fatigue syndrome: randomised controlled trial. British Medical Journal 340, 1777.

White, P.D., Goldsmith, K.A., Johnson, A.L., Potts, L., Walwyn, R., DeCesare, J.C., Baber, H.L., Burgess, M., Clark, L.V., Cox, D.L., Bavinton, J., Angus, B.J., Murphy, G., Murphy, M., O'Dowd, H., Wilks, D., McCrone, P., Chalder, T. and Sharpe, M. 2011: Comparison of adaptive pacing therapy, cognitive behaviour therapy, graded exercise therapy, and specialist medical care for chronic fatigue syndrome (PACE): a randomised trial. The Lancet $377,823-36$. 
154 Kerin bayliss et al.

\section{Appendix}

Table A1 BME patient and carer demographics

\begin{tabular}{|c|c|c|c|c|c|}
\hline ID number & Gender & Age & Ethnicity & Severity of CFS/ME & $\begin{array}{l}\text { Number of years } \\
\text { since diagnosis }\end{array}$ \\
\hline Patient 1 & Male & 61 & Indian & Severe & 22 \\
\hline Patient 2 & Female & 37 & Pakistani & Moderate/severe & 7 \\
\hline Patient 3 & Female & 52 & Pakistani & Mild/moderate & Self-diagnosed \\
\hline Patient 4 & Female & 32 & Other white & Mild/moderate & 2 \\
\hline Patient 5 & Male & 35 & Indian & Moderate (recently recovered) & 1 \\
\hline Patient 6 & Female & 38 & Pakistani & Mild/moderate & 2.5 \\
\hline Patient 7 & Female & 48 & Pakistani & Moderate & 2 \\
\hline Patient 8 & Male & 38 & Pakistani & Mild & 6 \\
\hline Patient 9 & Female & 40 & Black British & Moderate & 3 \\
\hline Patient 10 & Female & 39 & Black British & Mild & Self-diagnosed \\
\hline Patient 11 & Female & 82 & Pakistani & Moderate & Self-diagnosed \\
\hline Carer 1 & Female & 57 & Indian & Carers for husband: severe & 22 \\
\hline Carer 2 & Male & 71 & Pakistani & Cares for his wife: moderate/severe & 8 \\
\hline
\end{tabular}

$\mathrm{BME}=$ Black and minority ethnic; $\mathrm{CFS} / \mathrm{ME}=$ chronic fatigue syndrome/myalgic encephalitis.

Table A2 Health-care professional details

\begin{tabular}{|c|c|c|c|c|}
\hline Health Professional ID & Gender & Ethnicity & $\begin{array}{l}\text { Number of years } \\
\text { qualified }\end{array}$ & List size \\
\hline GP 1 & Female & White British & 24 & 5800 (45\%BME) \\
\hline GP 2 & Male & White British & 24 & 6300 (7\% BME) \\
\hline GP 3 & Female & White British & 14 & 6300 (51\% BME) \\
\hline GP 4 & Female & White British & 10 & 16000 (60\% BME). \\
\hline GP 5 & Female & Pakistani & 6 & 1640 (<1\% BME) \\
\hline GP 6 & Male & Pakistani & 8 & 8150 (1\% BME) \\
\hline GP 7 & Female & White British & 8 & 18000 (5\% BME) \\
\hline GP 8 & Female & White British & 16 & 5000 (50\% BME) \\
\hline GP 9 & Male & Pakistani & 8 & 7000 (5\% BME) \\
\hline PN 1 & Female & White British & 8 & 6300 (60\% BME) \\
\hline PN 2 & Female & White British & 8 & 7500 (15\% BME) \\
\hline PN 3 & Female & Pakistani & 5 & 2700 (70\% BME) \\
\hline PN 4 & Female & White British & 20 & 11000 (5\% BME) \\
\hline PN 5 & Female & White British & 12 & 7500 (18\% BME) \\
\hline $\begin{array}{l}\text { CFS/ME Specialist } 1 \\
\text { (physiotherapist) }\end{array}$ & Female & White British & $\begin{array}{l}20 \text { (worked in } \\
\text { CFS/ME } 10 \text { years) }\end{array}$ & $\mathrm{n} / \mathrm{a}$ \\
\hline $\begin{array}{l}\text { CFS/ME Specialist } 2 \\
\text { (specialist nurse) }\end{array}$ & Female & White British & $\begin{array}{l}22 \text { (worked in } \\
\text { CFS/ME field } 13 \text { years) }\end{array}$ & $\mathrm{n} / \mathrm{a}$ \\
\hline $\begin{array}{l}\text { CFS/ME Specialist } 3 \\
\text { (specialist nurse) }\end{array}$ & Female & White British & $\begin{array}{l}18 \text { (worked in } \\
\text { CFS/ME } 10 \text { years) }\end{array}$ & $\mathrm{n} / \mathrm{a}$ \\
\hline $\begin{array}{l}\text { CFS/ME Specialist } 4 \\
\text { (physiotherapist) }\end{array}$ & Male & White British & $\begin{array}{l}20 \text { (worked in } \\
\text { CFS/ME } 8 \text { years) }\end{array}$ & $\mathrm{n} / \mathrm{a}$ \\
\hline
\end{tabular}

$\mathrm{GP}=$ general practitioner; $\mathrm{BME}=$ Black and minority ethnic; $\mathrm{PN}=$ practice nurse; $\mathrm{CFS} / \mathrm{ME}=$ chronic fatigue syndrome/myalgic encephalitis. 
Table A3 BME community leader details

\begin{tabular}{llll}
\hline Community leader ID & Gender & Ethnicity & Role \\
\hline Community leader 1 & Male & Indian & Leader of a religious temple \\
Community leader 2 & Male & Pakistani & Manager of a community centre \\
Community leader 3 & Male & Pakistani & Manager of a community centre \\
Community leader 4 & Female & Pakistani & Manager of a national community centre \\
Community leader 5 & Female & Pakistani & Manager of a well-being and mental health charity \\
\hline
\end{tabular}

$\mathrm{BME}=$ Black and minority ethnic. 